\title{
LAS REFORMAS MÁS IMPORTANTES DEL BGB DESDE SU PROMULGACIÓN EN 1900, CON ESPECIAL REFERENCIA AL DERECHO DE OBLIGACIONES*
}

\section{THE MOST RELEVANT AMENDMENTS OF THE BGB SINCE IT WAS ENACTED IN 1900, WITH SPECIAL REFERENCE TO THE LAW OF OBLIGATIONS}

\section{ANDREas WaCkE*}

El tema de este trabajo es la continuación de mi primera ponencia pronunciada en Chile hace siete años, en 2005, con ocasión del Congreso Internacional de conmemoración de la promulgación del Código Civil chileno, organizado en la Pontificia Universidad Católica de Valparaíso por don Alejandro Guzmán Brito. Mi tema de entonces rezaba: "La codificación del Bürgerliches Gesetzbuch alemán después de un siglo"1.

\footnotetext{
* Este trabajo forma parte del Proyecto Anillo de Investigación Asociativa, en Ciencias Sociales, "Estudios Histórico-Dogmáticos de Derecho Patrimonial Privado: una mirada a los artículos de los Libros II y IV del Código Civil de Chile", SOC 1111, de CONICYT.

** Prof. Dr. h. c. mult., LLD h. c., Universidad de Colonia. E-Mail: Andreas.Wacke@uni-koeln.de. El texto tiene su origen en las conferencias pronunciadas en la Universidad de Antofagasta, en la ciudad de Santiago de Chile en la Pontifica Universidad Católica de Chile y Universidad de los Andes y en Valparaíso en la Pontificia Universidad Católica de Valparaíso (noviembre 2012); además en Madrid en las Universidades Autónoma y Carlos III (febrero 2013); y últimamente en la Universidad de Salamanca, en el III Curso Internacional de Derecho Romano, organizado por la Schola Serviana Iuris Romani (Dir. PatricioIgnacio Carvajal). Agradezco a mis anfitriones: Prof. Dr. Patricio Lazo González, Prof. Dr. Patricio-Ignacio Carvajal, Profa ${ }^{a}$ Dr ${ }^{a}$. María de los Ángeles Soza Ried, Prof. Dr. Alejandro Guzmán Brito, Prof. Dr. José María Miquel, Prof. Dr. Jorge Caffarena y Prof ${ }^{a}$. Dra ${ }^{a}$. Amelia Castresana.

1 Trabajos expuestos en el Congreso Internacional celebrado para conmemorar la promulgación del Código civil chileno. Wacke, Andreas (2007): "La
}

\section{LA SISTEMÁTICA DEL BGB}

El BGB, nuestro Código civil alemán, que entró en vigencia el 1 de enero de 1900, fue fruto de veinticinco años de esfuerzos de preparación, y representa el punto final de la doctrina pandectística. De acuerdo con los tratados de Derecho de las Pandectas (por ejemplo, los de Bernhard Windscheid o de Heinrich Dernburg), consta el BGB de cinco libros: Parte general, Obligaciones, Derechos Reales, Derecho de Familia y Sucesiones. Por tanto, a diferencia de lo que sucedía con la tradicional sistemática derivada de Gayo (personas, cosas, acciones), sostenida por ejemplo en el Code civil francés y en Código civil español: el BGB sitúa el Derecho de Obligaciones por delante de los derechos reales. La razón para esa anteposición, propuesta por primera vez por el famoso profesor de Heidelberg Karl Adolf von Vangerow (1808-1870) en su manual de Pandectas, en torno al año 1860 , es que la conclusión del contrato antecede temporalmente al negocio real que le sirve de cumplimiento: a

codificación del Bürgerliches Gesetzbuch alemán después de un siglo", en Guzmán, Alejandro (edit.), El Código civil de Chile (1855-2005). Trabajos expuestos en el Congreso Internacional celebrado para conmemorar su promulgación (Santiago, LexisNexis) pp. 683-700. 
la compraventa le sigue la transmisión de la propiedad. Los contratos transmisivos sirven como "títulos" para la adquisición, ellos preparan así la mutación de la atribución real (una "Zuordnungsänderung").

\section{EVOLUCIONES MÁS IMPORTANTES, ESPECIALMENTE EN EL DERECHO DE FAMILIA Y DE SUCESIONES 2}

En una mirada al transcurso de estos 110 años de su vigencia, puede decirse que el BGB ha demostrado ser un gran Código civil. En lo que se refiere al contenido y a la precisión terminológica, puede incluso decirse que es un Código ejemplar. Cada expresión y cada concepto del BGB tiene exclusivamente una sola significación, y no varias diferentes (como lo sucede en el Code civil francés). Tras la Segunda Guerra Mundial, nuestro BGB fue literalmente adoptado por Grecia en 1946, y recientemente, en el año 1997, en un formato más simplificado, por el nuevo Estado de Georgia, en la región del Cáucaso ${ }^{3}$.

\footnotetext{
2 Todas las modificaciones al BGB, hasta el año 1998 (salvo la modernización del Derecho de las Obligaciones), han sido completamente reimpresas, en la Synopse 1896-1998 en los comentarios de Staudingers al BGB, redactor Strätz, HansWolfgang (Berlin, 1998) pp. 1736. Para la historia dogmática es fundamental el de Schmoeckel, Mathias et alii emitido por Historisch-Kritische Kommentar zum BGB [HKK] Band I Allgemeiner Teil (Tübingen, 2003); Band II Schuldrecht, allgemeiner Teil (Tübingen, 2007).

3 El Código de Georgia contiene 1500 artículos (al igual como el Allgemeines Bürgerliches Gesetzbuch de Austria, un poco más de la midad del BGB alemán). Como los manuales de Derecho Romano sigue el sistema de Gayo: el libro segundo abarca el Derecho de cosas, el libro tercero el de las Obligaciones. Existe una traducción al alemán, realizada por la Deutsche Gesellschaft für Technische Zusammenarbeit.
}

Con todo, el progreso jurídico no se detuvo con la entrada en vigor del BGB en el año 1900. Tanto la doctrina como la jurisprudencia y el legislador, han seguido impulsando mutaciones y llenando sus lagunas. Las partes del BGB que se han demostrado más estables son el Derecho de cosas y el de la Herencia. Pero incluso en este último libro quinto sobre sucesiones fue necesario introducir algunos cambios, por ejemplo para reforzar la posición del cónyuge sobreviviente. En la versión inicial del $\mathrm{BGB}$, el viudo o la viuda que concurría con hijos recibía un cuarto de la herencia, y si no había hijos un medio del caudal hereditario. Hoy día el cónyuge supérstite recibe como pago de su pretensión a las ganancias patrimoniales habidas por el otro cónyuge, la mitad de los bienes si concurre con hijos, y tres cuartas partes si no existen hijos.

Además, se ha mejorado la posición de los hijos no matrimoniales. Hasta el año 1969 se consideraba que los hijos extramatrimoniales no tenían vínculo de parentesco con su padre ${ }^{4}$, por lo cual no tenían ningún derecho a la herencia, sino sólo un derecho de alimentos limitado en el tiempo. Tras el año 1969 recibían un trato especial, que hacía que tuvieran un derecho de crédito al doble de la cuota legitimaria cuando concurrían con parientes o con el cónyuge supérstite del fallecido ( $\$ 1934$ a del BGB versión antigua). Hoy en día, todo eso se ha superado, y no sólo en Derecho de sucesiones, sino en todo el Derecho privado, ya que

\footnotetext{
$4 \$ 1589$ párrafo 2 versión original del BGB: "Un hijo ilegítimo y su padre no se consideran emparentados (o parientes)". El BGB seguía aquí todavía el concepto romano del parentesco agnaticio. Esta versión del BGB estuvo vigente hasta 1955 y fue traducida al español por Melon Infante Código civil alemán, Apéndice al Tratado de Derecho civil por Enneccerus/Kipp/Wolff (Barcelona, 1955).
} 
la posición de los hijos extramatrimoniales está totalmente equiparada a la de los matrimoniales. El Derecho de familia no hace ya distinción ninguna entre ellos.

\section{CONSECUENCIAS DE LAS DOS GUERRAS MUNDIALES}

1. Hasta el inicio de la Segunda Guerra Mundial el BGB permaneció sustancialmente invariado. Una novedad de cierta importancia, la supuso el Reglamento sobre el derecho de superficie del año 1919, la primera ley promulgada por la Asamblea Nacional reunida tras la Primera Guerra Mundial. El derecho de superficie permite la construcción de un edificio en suelo ajeno. Dada la escasez de viviendas existente tras la Primera Guerra Mundial, era necesario estimular la construcción de casas mediante esta figura. Ésta, permite que el superficiario no adquiriere la propiedad del terreno, sino, que pagase por el uso una renta al propietario. Normalmente, la cuantía de esa renta debida al propietario del suelo es menor que los intereses que se han de pagar a los bancos por las cantidades obtenidas mediante crédito hipotecario para adquirir el suelo. El derecho de superficie representa una excepción al principio del ius civile romano "superficies solo cedit", que ya era reconocido por el edicto del pretor en el Derecho romano (Dig. 43,18). Como jurista europeo me sorprende que países como Chile o Sudáfrica no conozcan esta ingeniosa institución.

2. También las consecuencias de una guerra -esta vez de la Segunda Guerra Mundial- marcaron la necesidad de promulgar en 1951 una ley sobre propiedad horizontal o de viviendas (algo tardía, si se la compara con otros países que han introducido esta institución ya antes).

\section{EL PERIODO DEL NACIONALSOCIALISMO}

Muchas fueron las reformas legales introducidas durante la época del nacionalsocialismo y durante la Segunda Guerra Mundial. Una consecuencia del "Anschluss", de la incorporación de Austria en el año 1938, fueron la Ley de matrimonio y la Ley testamentaria. Ambas leyes se dictaron con la finalidad de unificar el régimen jurídico de Austria y Alemania en estas dos materias. También se introdujo en Austria el Código de comercio alemán (donde todavía está en vigor, mientras que las otras dos leyes mencionadas luego fueron abrogadas). Al poco tiempo de terminar la Segunda Guerra Mundial, el Comité de Control de las cuatro potencias aliadas (der Alliierte Kontrollrat der vier Besatzungsmächte) depuró la Ley de matrimonio de las normas de tenor nacionalsocialista, pero se mantiene en vigor todavía durante muchos años; sólo lentamente, paso a paso, volvieron a reintegrarse sus disposiciones dentro del BGB. En cambio, la Ley de testamento fue pronto asumida dentro del BGB, mediante una Ley del año 1953 titulada "Ley para la reconstrucción de la unidad jurídica en el ámbito del Derecho civil" (Gesetz zur Wiederherstellung der Rechtseinheit auf dem Gebiete des Bürgerlichen Rechts).

\section{LA PROTECCIÓN DE LOS ARRENDATARIOS}

Han sido también reintroducidas en el BGB las disposiciones especiales sobre la protección de los arrendatarios. Antes de su reincorporación, fueron depuradas de los elementos coyunturales del tiempo de posguerra que las vio nacer. La elevación del precio de la renta solo pueden llevarse a 
cabo en el marco de un procedimiento muy regulado, $\$ \$ 557$ y siguientes del BGB. En caso de muerte del arrendatario, su cónyuge, sus hijos u otras personas que convivan con él pueden continuar en su posición, $\$$ 563 BGB.

\section{DESCODIFICACIÓN Y RECODIFICACION}

El movimiento pendular entre codificación y descodificación observado por Natalino Irti (nacido el año 1936), conocido civilista en la Universidad "La Sapienza" de Roma, es fácilmente constatable en el Derecho alemán de las Obligaciones. Según Irti, vivimos hoy en una época de "descodificación" que se han dictado en los últimos años para atender a diversas necesidades, ha provocado que falte la necesaria tranquilidad para sistematizar las nuevas normativas a la luz de principios comunes. En los decenios transcurridos desde el final de la Segunda Guerra Mundial se han dictado muchas normas especiales, la mayoría de ellas destinadas a proteger a los consumidores. Una vez que, después de la caída de la muralla de Berlín y de la cortina de hierro entre ambas partes de Alemania en el año 1989, se reconstruyó la unidad jurídica de la República Federal del oeste con la antigua DDR del este -a la que muchos esfuerzos se dedicaron durante más de una década-, nuestro legislador se tomó el tiempo para abordar una reforma sistemática de todo el

\footnotetext{
5 Irti, Natalino (1999): L'età della decodificazione (Milano, Giuffrè, cuarta edición). Véase los trabajos presentados en el mencionado Congreso (supra nt. 1) sobre "Descodificación y recodificación del Derecho civil en Chile" de Corral, Hernán; Baraona, Jorge; Domínguez, Ramón y FigueroA, Gonzalo, pp. 639680.
}

Derecho de Obligaciones: al inicio del año 2002, con la "Ley de modernización del Derecho de Obligaciones", se reintrodujeron en el BGB muchas materias que habían quedado reguladas fuera del BGB mediante leyes especiales ${ }^{6}$. Voy ahora a tratar de dar una visión panorámica de esa legislación, sin pretensión de exhaustividad alguna.

\section{DIRECTIVAS EUROPEAS}

Toda esta legislación está motivada por el objetivo de lograr una armonización jurídica dentro de la Unión Europea. El Parlamento europeo y el Consejo pueden dictar Reglamentos y Directivas. Los Reglamentos tienen eficacia directa como Derecho inmediatamente aplicable en cada Estado miembro (Art. 249 párrafo 2 del Tratado de la Comunidad Europea), pero son poco frecuentes. Las Directivas, por otro lado, son mucho más habituales, pero requieren de su transposición por los Estados miembros (Art. 249 párrafo 3 del Tratado de la Comunidad Europea). A veces se realiza esta transposición con lentitud. La transposición requiere mucho más esfuerzo que una simple traducción, ya ella no siempre

6 Traducción al español Vives Montero, por María Luisa (2002): “Traducción de la Reforma 2002 del BGB", Anuario de Derecho civil, tomo LV, fascículo III: pp. 1229-1310. Respecto de este, véase Albiez Dohrmann (2002): "Un nuevo Derecho de obligaciones: La Reforma 2002 del BGB”, Anuario de Derecho civil, tomo LV, fascículo III: pp. 1133-1227; Las obras de ZimmermanN, Reinhard, traducidos al Castellano son: El nuevo Derecho alemán de obligaciones. Un análisis desde la Historia y el Derecho comparado (trad. Esther Arroyo i Amayuelas, Barcelona, Bosch, 2008); Derecho romano, derecho contemporáneo, derecho europeo: La tradición de derecho civil en la actualidad (trad. Javier M. Rodríguez Olmos, Universidad Externado de Colombia, 2010); Derecho de obligaciones: Estudios (trad. Antoni Vaquer Aloy, Editora y Distributora Ediciones Legales E.I.R.L., Lima-Perú, 2012). 
es fácil. En caso de que los plazos previstos por una Directiva no se cumplan, pende sobre los Estados incumplidores la amenaza de una sanción económica. En el caso de las Directivas para la protección a los consumidores, nuestro legislador ha cumplido con el plazo prescrito: 31 de diciembre del año 2001; exactamente el 1 de enero de 2002 la nueva legislación entró en vigor. El legislador alemán, para que resulte claro que está cumpliendo con sus deberes, suele comenzar esas normas de transposición indicando en una nota al pie de página en el comienzo de la ley: "estas normas se dictan para trasponer la Directiva núm... (fecha) del Parlamento Europeo y del Consejo (con indicación del lugar de la publicación)...”.

La finalidad de la mayoría de estas leyes es la protección de los compradores y de los consumidores. En Alemania, dicha protección existía ya antes de que se dictaran esas normas europeas. Con todo, nuestro legislador ha aprovechado la transposición de las Directivas europeas para armonizar dichas normas en cuanto a su contenido, para mejorarlas, y para introducirlas en el BGB. Con ello han quedado codificadas en el sentido propio, de manera que no se puede considerar que cada ley aislada constituya por sí misma una codificación. De acuerdo con Jeremy Bentham (1748-1832) entendemos por código en sentido propio un resumen sistemático de las materias de un determinado ámbito jurídico realizado conforme a un plan preconcebido ${ }^{7}$. Pues bien, puede decirse que nuestro legislador

\footnotetext{
7 Guzmán, Alejandro (2007): "El origen y desarrollo de la idea de codificación del Derecho" en Guzmán, Alejandro (edit.), El Código civil de Chile (1855-2005), Trabajos expuestos en el Congreso Internacional celebrado para conmemorar su promulgación (Santiago, LexisNexis) pp. 43 y siguientes.
}

ha buscado realizar una verdadera recodificación. Con ella, el Derecho de consumidores deja de ser un Derecho privado especial. Un ejemplo en contra es la antigua Ley de 1896 de venta a plazos (Abzahlungsgesetz): ésta constituía una ley especial, dictada para atender a las necesidades de compradores con menor capacidad adquisitiva. Dicha ley no fue incorporada en el BGB antes de su entrada en vigor el 1 enero de 1900, sino que se mantuvo fuera del BGB como ley especial. Luego en al año1990 fue ampliada en una Ley de protección del crédito al consumo (Verbraucherkreditgesetz), y ahora, desde el 2002, sus normas figuran dentro del BGB ocupando los $\$ \$ 491$ y siguientes.

\section{LA PROBLEMÁTICA DE LA UBICACIÓN}

La transposición de leyes especiales, su incorporación en un código ya perfectamente ordenado, es un arte, comparable a la integración de nuevas piezas en un edificio histórico ya erigido y habitado. Un problema difícil es ya su ubicación. Ciertos límites externos del BGB ya dieron lugar a dificultades para integrar en él las citadas normas. Sus 2385 parágrafos parecía una frontera infranqueable: la posibilidad de dar una nueva numeración a todos parágrafos del código no parecía adecuada, ya que una modificación de los ya existentes hubiese dado lugar a muchas dificultades en la aplicación práctica. Tampoco parecía solución, el añadir las normas sobre protección a los consumidores como un apéndice final, pues eso hubiese hecho que siempre se las considerase como normas especiales de Derecho privado, haciendo además saltar por los aires la división del material del BGB en cinco libros. Aquí se ve una dificultad derivada del hecho de que el De- 
recho de Obligaciones no figure al final del $\mathrm{BGB}$, como en otros países. En vista de esta dificultad, se decidió incluir en los lugares respectivos nuevos parágrafos con números seguidos de una letra. Por ejemplo, los 13 largos parágrafos dedicados a los contratos de viajes combinados, recibieron los números que van del $651 \mathrm{a}$ al $651 \mathrm{~m}$. Regularlos en una ley especial hubiese dado pie a que con frecuencia hubiesen pasado desapercibidos. Actualmente, se quiere introducir en el BGB incluso normas específicas sobre el tratamiento médico ${ }^{8}$. Además, se ha conseguido dar mayor visibilidad a todas las normas del BGB haciendo que cada parágrafo reciba un título (un tipo de letrero o etiqueta), que ahora tiene eficacia oficial, es decir, pertenece al texto legal.

\section{SUSCRIPCIÓN Y FIRMA ELECTRÓNICA}

Para dar respuesta a las nuevas posibilidades de comunicación en el tráfico comercial, se han incluido en la parte general del BGB dos modalidades aligeradas de forma, que responden también a Directivas comunitarias: (1) Por una parte, la exigencia de forma escrita puede sustituirse por una forma electrónica, $\$ 126$ a del BGB; en lugar de la firma manual puede emplearse así una "firma electrónica cualificada". Sin embargo, la obtención de esa firma electrónica lleva consigo un procedimiento bastante complicado, por eso es difícil que perso-

\footnotetext{
8 Los romanos cualificaban el contrato con el médico como contrato de obra (locatio conductio operis), y no (como en la mayoría de los casos lo hacemos hoy) como contrato de servicios. Véase Wacke, Andreas (1996): „Die Anerkennung der Medizin als ars liberalis und der Honoraranspruch des Arztes“, Zeitschrift der Savigny-Stiftung für Rechtsgeschichte, romanistische Abteilung [SZ] 113: pp. 382-421.
}

nas físicas singulares la utilicen. Además, en casos de que la exigencia de forma responda a cierta necesidad de protección (como sucede, por ejemplo, con la asunción de una fianza, $\$ 766$ frase 2 del BGB), la firma electrónica está expresamente excluida. (2) A la suscripción se renuncia también en el caso de la llamada "forma textual", $\$ 126 b$ del BGB. En ella es suficiente una declaración de voluntad que "sea emitida en un modo escrito que permita su reproducción de forma duradera", y que su emisor y el final de la declaración puedan ser conocidos. Para esto basta su recepción en un ordenador del receptor. "Forma textual" (Textform) en su esencia significa forma electrónica (pero en este caso sin firma electrónica cualificada). Esta última transmisión de datos electrónicos sólo se toma como declaración válida cuando la ley expresamente lo permita, como sucede con las declaraciones de voluntad de naturaleza cuasi negocial, en las que la función de prevención de la suscripción ológrafa tiene menor trascendencia, tal como ocurre en meras ofertas o declaraciones de revocación, incluso en ciertos negocios jurídicos, como la elevación de la renta del arrendamiento, $\$ 558$ a párrafo 1 del BGB.

\section{LA PROTECCIÓN DE LOS CONSUMIDORES ${ }^{9}$}

1. Con cuestionables e injustos métodos, los consumidores se vieron habitualmente obligados a celebrar contratos onerosos, como por ejemplo a través de llamadas telefónicas, visitas no solicitadas al hogar, conversaciones en la calle. Medios preformulados generalmente con cláusulas con-

9 Véase Meder, Stephan (2011): Rechtsgeschichte (4. Auflage, Kap. 21). 
tractuales tipo, que recortan generalmente los derechos de los clientes. En el caso de los productos defectuosos ello puede producirles un daño.

Una serie de leyes especiales fueron publicadas en Alemania para proteger a los consumidores. Luego, las Directivas europeas reforzaron la protección a los consumidores y a los clientes; directrices que fueron implementadas, como ya he mencionado, a través de la integración de ellas en el BGB. Las nociones de 'consumidor' y 'empresario' ahora están definidos en los $\$ \$ 13$ y 14 del BGB.

Instrumentos de protección al consumidor son, sobre todo, el deber de información que recae sobre los empresarios, y los derechos de revocación para el cliente. Un especial Reglamento en la normativa del deber de información se encuentra en el detalle de los requisitos de los cuales los clientes deben ser informados. La normativa se aplica a los contratos a distancia, los derechos de uso en "tiempo compartido", los contratos en las transacciones electrónicas, los contratos de viaje y las entidades de crédito. En éstos los clientes deben ser aclarados sobre su derecho de revocación y sobre las eventuales consecuencias. Si falta dicha aclaración, el cliente puede, en principio, revocar incluso después de la expiración del período designado. El derecho temporal de revocar se transforma así en un derecho permanente.

2. La Ley de Condiciones Generales de Contratación de 1976 fue integrada (en contra de la oposición de conocidos juristas) en forma de bloque en el BGB. Fue cuestionado, si esta materia tenía que ubicarse dentro de la Parte General (como anexo al los parágrafos que tratan de la declaración de la voluntad y de la conclusión del contrato, $\$ \$ 116$ ss. y 145 ss.), o en el Libro segundo, del Derecho de las Obligaciones. Se decidió a favor de su posición bajo las reglas generales del derecho contractual, y se añade por ello una nueva sección 2, intitulada "Formación (o configuración, "Gestaltung") de relaciones negociales mediante condiciones generales de la contratación”, $\$ \$$ 305-310. Las condiciones generales formarán parte del contrato, sólo si el empresario (llamado "predisponente", Verwender) (1.) haga una referencia expresa a ellas o bien las exhiba de manera claramente visible, y (2.) facilite al cliente la posibilidad razonable de tener conocimiento de su contenido. Lo anterior, permite que el cliente esté consciente de su existencia y pueda razonablemente entenderlos y estar de acuerdo con ellos, sea expresa o tácitamente, $\$ 305$ párrafo 2 del BGB. Los acuerdos contractuales individuales tienen prioridad, $\mathbb{S} 305 \mathrm{~b}$. Los términos inusuales que el cliente no necesita calcular, no forman parte del contrato. Las eventuales dudas que puedan emanar en la interpretación perjudicarán al predisponente, $\mathbb{\$}$ 305 c párrafo 2 , de acuerdo con la antigua regla romana ambiguitas contra stipulatorem (quia clarius loqui potuisset). La jurisprudencia ha desarrollado además el principio de la transparencia, que ahora está regulado en el $\$ 305$ c párrafo 1 frase 2 del BGB.

3. En contra de las frecuentes insistencias a la puerta de la casa de un cliente, para que se suscriba por ejemplo a una revista, se publicó en el año 1986 la Ley de revocación de negocios a domicilio y otros negocios análogos. La denominación "negocios a domicilio" es demasiado amplia, porque siempre cuando los contratos son firmados fuera de los locales de las empresas, incluidos los eventos recreativos (por ejemplo, en excursiones o acontecimientos deportivos) o en el lugar de trabajo del 
cliente, caben bajo la norma. El cliente está protegido por el derecho temporal de revocación, del cual se debe encontrar informado. Estas reglas de la ley especial del año 1986 han sido incorporadas sin cambios materiales en el $\$ 312$ BGB bajo el subtítulo "Formas especiales de distribución". Al igual que la mayoría de las normas protectoras, son unilateralmente irrenunciables (jus cogens en el sentido unilateral): de ellos se pueden apartar las partes solo en beneficio, no en detrimento del cliente, $\$ 312 \mathrm{i}$, frase 1 , véase $\$ 506$ BGB.

4. En la práctica, especialmente importante es la competencia territorial. Anteriormente, en condiciones generales, los empresarios señalaban como competente para cualquier controversia, el tribunal de su propio domicilio comercial. En los contratos a distancia, esto era muy perjudicial para los clientes. Por lo tanto, esta práctica se ha visto gravemente restringida por una reforma legal sobre la competencia territorial. Una prórroga de la competencia la pueden pactar ahora sólo los comerciantes entre sí, porque ellos no necesitan tal protección, de acuerdo a lo señalado en el $\S$ 38 ZPO (Ley de enjuiciamiento civil). En las controvercias que nacen de los negocios a domicilio, el tribunal de la residencia del cliente tiene competencia exclusiva, por disposición del $\$ 29$ c ZPO.

5. Los contratos de consumo regulados ahora por el BGB son: la compra de bienes de consumo, $\$ \$$ 474-479, el arrendamiento de tiempo compartido de inmuebles (time-sharing, aprovechamiento por turnos), $\$ 481$ et seq, los créditos de consumo, $\$ \$ 491$ y siguientes, los contratos de financiamiento y entrega de suministros, $\$ \$ 400,505$.

\section{EL CAMBIO DEL MODELO SOCIAL}

La integración de todas estas disposiciones de protección contenidas en el BGB, significa el fin de un derecho privado especial. Para la relevancia práctica de la protección de los consumidores, se hizo esta incorporación sin mayores cambios o mejoras. Esta incorporación afecta principalmente a la estética de la legislación (que se complete). Sin embargo, para el estudio y la enseñanza en la Universidad, se recomendaría más bien la reserva del Código como el núcleo del derecho privado, sin disposiciones demasiado especiales (por ejemplo, sobre el contrato de viaje). Lo anterior, debido a que el Código es la herramienta primera y más importante del aprendizaje para el aula. Los principios rectores, que no se encuentran con total claridad establecidos en el BGB, amenazan con perderse en la maraña de normas especiales. El antiguo legislador del BGB partía del presupuesto que todos los ciudadanos en una sociedad liberal son iguales y autorresponsables de sus actos. Pero en la actualidad el derecho de protección al consumidor ha penetrado, como idea dominante, completamente en el Derecho de las Obligaciones del BGB. Una muestra de ello son en principio, las definiciones generales, que destacan a los consumidores y las empresas, $\$ \$ 13,14$. El modelo social subyacente del Código (en el sentido de Franz Wieacker 1908-199410) ha cambiado en el transcurso de un siglo.

10 Wieacker, Franz (1953): Das Sozialmodell der klassischen Privatrechtsgesetzbücher und die Entwicklung der modernen Gesellschaft (Karlsruhe, CF Müller) p. 30; Wieacker, Franz (1967): Privatrechtsgeschichte der Neuzeit (Göttingen, Vandenhoeck \& Ruprecht) p. 620. 


\section{CODIFICACIÓN DE FIGURAS DOCTRINALES Y CONSUETUDINARIAS}

1. El cambio puramente formal de la ubicación de las normas de protección, causó problemas prácticos de ajuste, en los años siguientes a su promulgación. La antigua jurisprudencia y doctrina, fueron utilizables sólo con dificultad. Se tuvo que recurrir entonces a yuxtaposiciones sinópticas (donde existe como una obra privada).

La mayor parte del desplazamiento puramente técnico de leyes especiales en materia de protección del consumidor en el $\mathrm{BGB}$, sin cambio sustancial, no tendría aún la denominación "Modernización del Derecho Obligacional". Sin embargo con éstas, fueron reformadas además, algunas áreas principales del Derecho Privado, particularmente la prescripción y el incumplimiento de la prestación. Algunos otros institutos no escritos se desarrollaron praeter legem en el siglo pasado; y esto hizo que el texto de la ley no reflejara el verdadero Derecho aplicado en la práctica, por lo que necesitaba de una reforma. Así fueron codificadas, aquellas figuras jurídicas que existían antes solo en la elaboración doctrinaria y jurisprudencial del derecho consuetudinario, tales como la culpa in contrahendo ${ }^{11}$, los contratos con eficacia de protección frente a terceros $(\$ 311$ párrafo 3 BGB: por ejemplo, los contratos de arrendamiento incluyen deberes de protección también frente a los niños del arrendatario), la lesión positiva de las obligaciones, seguido de la infracción del deber jurídico, la alteración de la base

$11 \$ 311$ apart. 2 núm. 1: "Una relación obligatoria con deberes según lo previsto en el $\$ 241$, apart. 2 nace también mediante la iniciación de negociaciones contractuales...”. del negocio ( $\$ 313$ BGB), el desistimiento de relaciones obligatorias duraderas por una causa importante $(\$ 314 \mathrm{BGB})$. En esto radica lo significativo de la reforma, quizás también digna de ser imitada por otros países. Respecto a todas, se habían desarrollado, ya desde los años 1980, complejas propuestas de articulación.

\section{DESDE LA IMPOSIBILIDAD AL INCUMPLIMIENTO DE LA PRESTACIÓN}

El principal cambio con la ley de modernización del derecho obligacional se refiere al incumplimiento de la prestación. El concepto central de la antigua ley era la imposibilidad, impossibilitas nulla obligatio (\$306 antigua versión). Las diferencias del concepto eran objetivas y subjetivas, culpabilidad o no culpabilidad. (Más precisamente se habla hoy de "responsabilidad", porque el deudor es también responsable de faltas de sus dependientes o agentes). A esa regla de la imposibilidad se añadió la figura de la mora. En general, antiguamente, los casos de cumplimiento irregular no se regulaban. Para cerrar esta brecha, la doctrina y la práctica inventaron praeter legem la llamada lesión positiva del contrato. (Podía consistir también en una omisión). Además, según la doctrina de Rudolf von Jhering, se desarrolló la culpa in contrahendo. A pesar de no haberse puesto en marcha un contrato, la entrada en los tratos preliminares desencadena ya deberes de protección a favor de la otra parte. Uno de los primeros casos fue el conocido " $\mathrm{Li}$ noleumfall' (del rodillo de una alfombra): un gran rollo de alfombra cayó sobre un cliente que resultó herido. Las reclamaciones por incumplimiento del contrato (o en este caso, de futuro cuasicontrato como la 
culpa in contrahendo o culpa precontractual) son más favorables para las víctimas, porque la culpa del responsable se presume. En las reclamaciones por daños ex delicto, por otro lado, la víctima tiene que probar la culpa del responsable. La responsabilidad ex contractu es también por eso más favorable para la víctima, porque es más estricta la responsabilidad para los agentes y auxiliares del deudor (\$831 BGB).

El concepto central de hoy es el incumplimiento de la obligación; la norma básica es el $\$ 280$. El incumplimiento intencional o negligente obliga a pagar una indemnización. Así también se incluyen los casos de la anterior "lesión positiva del contrato". La culpa se presume, el deudor debe exculparse. Los daños y perjuicios "por incumplimiento" (el interés positivo) ahora se llaman prestación, "en lugar de cumplimiento". Antes el deudor debe tener un plazo razonable para rectificar su incumplimiento, de acuerdo a la nueva versión del $\$$ 281. Para las deudas de género no se requiere ninguna disposición especial (como antes, según la regla genus non perit), porque la responsabilidad objetiva del deudor (más allá del dolo y de la negligencia) puede tener lugar también a partir del contenido de la obligación ("sobre todo a partir de la asunción de un riesgo", de acuerdo a la nueva versión del $\$ 276$ ). La culpa in contrahendo está prevista específicamente en la nueva versión del $\$ 311$ párrafo 2 , la alteración de la base del negocio está en el $\$ 275$ párrafos 2-3.

Una novedad de la ley, sobre la mora del deudor, es que el deudor de dinero después de 30 días desde la recepción de la factura automáticamente cae en mora, $\mathbb{S}$ 286 párrafo 3.

\section{REFORMAS DE LA COMPRAVENTA Y DEL PRÉSTAMO}

1. Debe hacerse hincapié en la venta de bienes, cuando los bienes han sido enviados a los consumidores, sin que ellos los hayan solicitado, no desencadena ninguna obligación de pago, $\$ 241$ a, lo que fue siempre doctrina dominante.

2. Conocida es la distinción del Derecho romano entre los vicios materiales y defectos jurídicos de la cosa vendida. Esta diferencia ha sido abandonada con la revisión del contrato de compraventa - para mi disgusto ${ }^{12}$. Incluso el término "Wandelung", "redhibición", se ha suprimido. En ambos casos el comprador podrá, frente a un defecto de la cosa o una deficiencia del derecho, después del cumplimiento demandar otro remedio, $\$ \$ 437,439$ del BGB. El remedio puede consistir en una reparación, en la eliminación del defecto (Nachbesserung), o en la entrega de otra cosa sin defectos. Si estos remedios también fracasan, el comprador puede rescindir el contrato (zurücktreten) o reducir el precio proporcionalmente (mindern).

3. Por último, se pueden citar los cambios en el contrato de préstamo. La

\footnotetext{
12 La responsabilidad por vicios redhibitorios y el saneamiento por evicción no son comparables. Porque la afirmada falta del derecho del vendedor afecta la posición de un tercero y es raramente evidente. Véase Wacke, Andreas (1992): "Los presupuestos de la responsabilidad por evicción en Derecho romano y en Derecho comparado", Seminarios Complutenses de Derecho Romano, $\mathrm{N}^{\circ}$ 4: pp. 157-204 = WACKE (1996): Estudios de Derecho romano y moderno en cuatro idiomas (Madrid, Fundación Seminario de Derecho Romano "Ursicino Álvarez") pp. 319 y siguientes; WACKE, Andreas (2003): Recensión crítica a ERNST, Rechtsmängelhaftung (Tübingen, 1995), Zeitschrift der Savigny-Stiftung für Rechtsgeschichte, 120: pp. 266274.
} 
nueva versión distingue los préstamos de dinero y préstamos de cosas fungibles. Ambos están situados en diferentes lugares, pero diseñados de manera diferente a los de la antigua formulación. La antigua formulación entendía el préstamo como un contrato real ${ }^{13}$. Ahora es claramente un contrato consensual ${ }^{14}$. Existen también disposiciones específicas para las operaciones de crédito de consumo. Éstas deben constar por escrito con informaciones detalladas (ahora $\$ 492$ BGB). Si falta la forma por escrito, el contrato no es válido, a menos que el consumidor "reciba la cantidad o la exige o reclame el complimiento del préstamo" ( $\$ 494$ párrafo 2 BGB). Por consiguiente, en su núcleo, el préstamo concedido por un contrato de consumo sigue siendo contrato real.

\section{$X V$. LA REFORMA DE LA PRESCRIPCIÓN EXTINTIVA}

El antiguo plazo de prescripción era regularmente de 30 años. Esto procede del emperador Constantino el Grande, que en el siglo IV introdujo la longi temporis praescriptio. En el acelerado mundo de hoy, el tiempo de 30 años -excepto para inmuebles- es demasiado largo. Para las pretensiones cotidianas estaba establecido el plazo de

$13 \S 607$ antigua versión del BGB: "Quien ha recibido como mutuo dinero u otras cosas fungibles, está obligado a restituir al mutuante (prestamista) lo recibido en la misma especie, calidad y cantidad". El préstamo, sin embargo, fue reconocido ya antes por el BGB en $\$ 598$ como contrato consensual: "Por el contrato de comodato el comodante de una cosa se obliga a permitir gratuitamente al comodatario el uso de la cosa".

$14 \$ 488$ apart. 1, nueva versión: "Mediante el contrato de préstamo se obliga el prestamista a poner a disposición del tomador del préstamo una suma de dinero en la cantidad acordada...".
2 años a partir del final del año de su nacimiento. Los derechos de garantía legales en compraventa prescribían en 6 meses desde la fecha de la entrega, $\$ 477$ BGB antigua versión. Esto dio lugar a contradicciones. El derecho a reclamar la indemnización por daños y perjuicios por un delito, prescribía en 3 años a partir de que la víctima tuviera conocimiento de los daños y del autor del daño, $\$ 852$ BGB antigua versión. En los otros casos se iniciaba el plazo de la prescripción de manera puramente objetiva al final del año del nacimiento de la obligación, aunque el acreedor no pudiera saber todavía la existencia de su crédito y la identidad del deudor.

Bajo la nueva ley, el plazo de las prescripciones es generalmente de tres años. Comienzan a finales del año del nacimiento de la pretensión y el posible conocimiento del acreedor de los hechos constitutivos de la demanda, incluida la identidad del deudor. El plazo de prescripción depende, pues, tanto de un componente objetivo como de uno subjetivo. Sin conocimiento del deudor el plazo de la prescripción es de 10 años. Esto es satisfactorio. No me permite el tiempo entrar en detalles ${ }^{15}$.

15 Véase CaÑIZares, Laso (2003): "La prescripción en el BGB después de la reforma del Derecho de obligaciones, Estudios jurídicos en homenaje al profesor Luis Diez-Picazo I (Madrid, Editorial Cívitas) pp. 409-431. La reforma al derecho de prescripción contempla a lo menos dos defectos: 1. Dada por el comprador una cosa (como regularmente) bajo reserva de la propiedad, puede él, no obstante haber prescrito su pretensión en el pago del precio de la compra del contrato, renunciar a esta y reclamar nuevamente la cosa. $\$ 216$ párrafo 2 frase 2 BGB: "Si se reservado la propiedad, se puede producir la resolución del contrato incluso cuando el derecho garantizado haya prescrito". Esta violación en contra de los principios fundantes de la prescripción, que luego de la expiración ninguna parte puede exigir algo de la otra (se dice "El que tiene, él 
Estos son los rasgos más importantes de las reformas del BGB durante el siglo pasado y de la modernización del Derecho de las obligaciones en el BGB del año 2002. tiene"). Los comprobantes de los pagos hechos, los tiene que conservar siempre el comprador; así, la pretensión del precio de compra es prácticamente imprescriptible. Esta consecuencia es inaceptable. Luego de históricos Reglamentos precursores fue lo que quedó, cuando el acreedor (no como aquí el duedor) tiene la seguridad en su posesión (para todo Cod. iust. 7,39,7,5; año 525 p. Chr.). Véase Wacke, Andreas (2009): „Kritik an der „Unverjährbarkeit“ dinglich gesicherter Ansprüche. Für ein Erlöschen von Eigentumsvorbehalt und Grundpfand nach verjährter Forderung", Festschrift für Volker Beuthien, pp. 75-96.
- 2. Muy poco claras son la legislación y la jurisprudencia con respecto al plazo de la prescripción. En algunos casos empieza a correr el primer plazo con el recibo de la factura. Esta es una violación del principio Totiens praescribitur actioni nondum natae, quotiens nativitas est in potestate creditoris. Véase WaCKe, Andreas (2002): „Verjährungsbeginn nicht vor Rechnungserteilung? Die BGH-Rechtsprechung... im Widerspruch zu Grundprinzipien des Verjährungsrechts", Festschrift für Walter Jagenburg: pp. 953-979. 